\title{
An Analysis of Choosing Gravity Anomalies for Solving Problems in Geodesy, Geophysics and Environmental Engineering
}

\author{
Vytautas Puškorius ${ }^{1}$, Eimuntas Paršeliūnas ${ }^{2}$, Petras Petroškevičius ${ }^{3}$, Romuald Obuchovski ${ }^{4 *}$ \\ 1, 2, 3, ${ }^{4}$ Department of Geodesy and Cadastre, Environmental Engineering, \\ Vilnius Gediminas Technical University, Vilnius, Lithuania \\ 2,3,4 Institute of Geodesy, Environmental Engineering, \\ Vilnius Gediminas Technical University, Vilnius, Lithuania
}

Received 19 February 2020; accepted 20 April 2020

\begin{abstract}
Gravity anomalies provide valuable information about the Earth's gravity field. They are used for solving various geophysical and geodetic tasks, mineral and oil exploration, geoid and quasi-geoid determination, geodynamic processes of Earth, determination of the orbits of various objects, moving in space around the Earth etc. The increasing accuracy of solving the above mentioned problems poses new requirements for the accuracy of the gravity anomalies. Increasing the accuracy of gravity anomalies can be achieved by gaining the accuracy of the gravimetric and geodetic measurements, and by improving the methodology of the anomalies detection. The modern gravimetric devices allow to measure the gravity with an accuracy of several microgals. Space geodetic systems allow to define the geodetic coordinates and ellipsoidal heights of gravimetric points within a centimeter accuracy. This opens up the new opportunities to calculate in practice both hybrid and pure gravity anomalies and to improve their accuracy. In this context, it is important to analyse the possibilities of detecting various gravity anomalies and to improve the methodology for detecting gravity anomalies. Also it is important the correct selection of the gravity anomalies for different geodetic, geophysical and environmental engineering tasks. The modern gravity field data of the territory of Lithuania are used for the research.
\end{abstract}

Keywords: gravity anomalies, gravity field, quasigeoid, Free-air gravity anomalies, Faye anomalies, Bouguer anomalies, normal Earth's gravity field.

\section{Introduction}

Gravity anomalies provide valuable information on the Earth's gravity field. They express the difference between the measured value of gravity acceleration and its normal value defined by the accepted normal Earth's gravity field. Gravity anomalies are applicable for solving various problems in geodesy and geophysics related to investigation of the geoid and the quasigeoid (Hofmann-Wellenhof \& Moritz, 2006; Torge, 1989), searching for minerals and oil deposits in gravimetric prospecting activities (Bychkov et al., 2015) as well as for examining geodynamic processes in the Earth and establishing the orbits of various objects moving in the space around the Earth. The increasingly growing accuracy of solving the above-mentioned problems provides new standards for the accuracy of gravity anomalies as well. The accuracy of gravity anomalies can be improved by increasing the accuracy of gravimetric and geodetic measurements and improvement of methods for detection of the anomalies.

Earlier the normal gravity field was predetermined by the formula of normal gravity acceleration; however, at present the said field is most frequently predetermined by the equipotential ellipsoid of the Earth rotation (HofmannWellenhof \& Moritz, 2006; Torge, 1989; LaFehr \& Nabighian, 2012) that's parameters are chosen close to the relevant parameters of the Earth to the maximum possible extent. In addition, while choosing a geocentric gravitational constant for determining the normal field, the mass of the Earth is supplemented with the mass of the Earth's atmosphere. It is bound with increasing application of methods of space geodesy. In practice, upon taking into account the types of problems to be tackled, various gravity anomalies are applied (Hofmann-Wellenhof \& Moritz, 2006; Torge, 1989; Nozaki, 2006). For solving different problems, gravimetric materials from different periods are used, therefore the correct reduction calculations are of very high importance.

Use of modern gravimetric devices enables establishing the gravity acceleration with the accuracy of several microGals (Bychkov et al., 2015; Petroškevičius et al., 2014; Hinze et al., 2005). In addition to coordinates of the

\footnotetext{
*Corresponding author. E-mail: romuald.obuchovski@vgtu.lt
}

\section{Copyright (C) 2020 The Author(s). Published by VGTU Press}

This is an Open Access article distributed under the terms of the Creative Commons Attribution License (http://creativecommons.org/licenses/by/4.0/), which permits unrestricted use, distribution, and reproduction in any medium, provided the original author and source are credited. 
gravimetric station, means of space geodesy ensure the required centimetre-level accuracy of establishing the ellipsoid altitudes. In practice, this circumstance discloses new opportunities of applying clean gravity anomalies (not only the mixed ones) and increasing the accuracy of their establishing. Upon taking the said into account, it is purposeful to examine various opportunities for establishing the gravity anomalies and to improve the applicable methods. These issues are discussed upon in the paper. For the investigation, the data on gravity field of the territory of Lithuania are used. In 2016-2018, a new gravimetric survey of the territory of Lithuania was made; the root-mean square error of gravity acceleration established in its points is $0.021 \mathrm{mGal}$. Earlier the principal source of information on the gravity field of the territory of Lithuania was the gravimetric map (the scale 1:200 000) formed according to the data of the gravimetric survey formed in 1951-1962. For calculation of the anomalies, Helmert's normal gravity field was applied. At present, GRS80 normal gravity field is applied in Lithuania. In the paper, the changes of calculations of gravity acceleration anomalies and the corrections for them according to different algorithms are assessed.

\section{Free-air anomalies}

When the normal gravity field GRS80 is applied, the free-air gravity anomaly shall be expressed by the following formula (Hofmann-Wellenhof \& Moritz, 2006; Torge, 1989; Moritz, 1980; Petroškevičius, 2004; Birvydienė, 2014):

$$
\left(g-\gamma_{80}\right)=g_{z}-\gamma_{80}^{0}+\Delta \gamma_{80}(H)+\Delta g_{a}(H),
$$

here $g_{z}$ - the gravity acceleration measured on the Earth's surface; $\gamma_{80}^{0}-$ the normal gravity acceleration on the surface of the equipotential ellipsoid GRS80.

$$
\gamma_{80}^{0}=\gamma_{80 \mathrm{e}}^{0} \frac{1+k_{80} \sin ^{2} B}{\sqrt{1-e_{80}^{2} \sin ^{2} B}},
$$

$\gamma_{80 e}^{0}, e_{80}, k_{80}$ - parameters of the normal gravity field GRS80; $\mathrm{B}$ - geodetic latitude; $\Delta \gamma_{80}(H)$ - altitude correction obtained upon applying the vertical gradient of the normal gravity acceleration; $\mathrm{H}$ - the normal altitude of the point (in calculation of mixed anomaly) or the ellipsoidal altitude of the point (in calculation of clean anomaly); $\Delta g_{a}(H)-$ atmosphere-related correction.

When Helmert's normal gravity field is applied, the gravity acceleration on the surface of the ellipsoid is calculated in the Potsdam system according to the following formula:

$$
\gamma_{H}^{0}=978030\left(1+0,005302 \sin ^{2} B-0,000007 \sin ^{2} 2 B\right) .
$$

The difference between the values of gravity accelerations calculated according to the formulas (2) and (3) for points of the new gravimetric survey of Lithuania (total 35520 points) varies between $3.922 \mathrm{mGal}$ and $3.969 \mathrm{mGal}$. The average value of the difference is $3.944 \mathrm{mGal}$, and the standard deviation equals to $0.011 \mathrm{mGal}$.

For formation of the above-mentioned new gravimetric map of Lithuania, the vertical gradient of normal gravity acceleration $(0.3086 \mathrm{mGal} / \mathrm{m})$ was applied upon ignoring its dependence on the latitude. In GRS 80 field, the altitude correction shall be calculated according to the following formula (Torge, 1989):

$$
\Delta \gamma_{80}(H)=0,30877\left(1-0,00142 \sin ^{2} B\right) H-0,75 \cdot 10^{-7} H^{2},
$$

here the altitude $H$ shall be expressed in $\mathrm{m}$, and the correction is obtained in $\mathrm{mGal}$.

Within the territory of Lithuania, the normal altitudes of points on the Earth's surface distribute between 0 and $300 \mathrm{~m}$.

After calculation of altitude correction for points of the new gravimetric survey, it was found that an ignorance of the latitude causes errors up to $-0.042 \mathrm{mGal}$. The average value of an error is $-0.014 \mathrm{mGal}$, and the standard deviation is $0.007 \mathrm{mGal}$. The distribution of errors in the territory is shown in Figure 1.

In the opinion of geophysicists (Bychkov et al., 2015), while carrying out gravity acceleration measurements, it would be purposeful to measure the vertical gradient as well, because anomalies of the real vertical gradient of gravity acceleration provide high-value information on the composition of the Earth's crust. It would improve considerably the efficiency of gravimetric prospecting.

In the value of the geocentric gravitational constant for GRS80 field, the mass of the Earth's atmosphere ( $G M=$ $3986005 \cdot 108, \mathrm{~m}^{3} \mathrm{~s}^{-2}$ ) was taken into account as well (Moritz, 1980). So, in this normal field, because of the increased mass of the Earth, an increased value of normal gravity acceleration is obtained. Therefore in calculations of gravity anomalies, the pull of the Earth's atmosphere that depends on the altitude of the point on the Earth's surface should be assessed. The atmosphere correction (Hinze et al., 2005; Moritz, 1980) shall be expressed by the following formula:

$$
\Delta g_{a}(H)=0,874-0,99 \cdot 10^{-4} H+0,356 \cdot 10^{-8} H^{2},
$$

here the point's altitude is expressed in $\mathrm{m}$, and the correction is obtained in $\mathrm{mGal}$. 


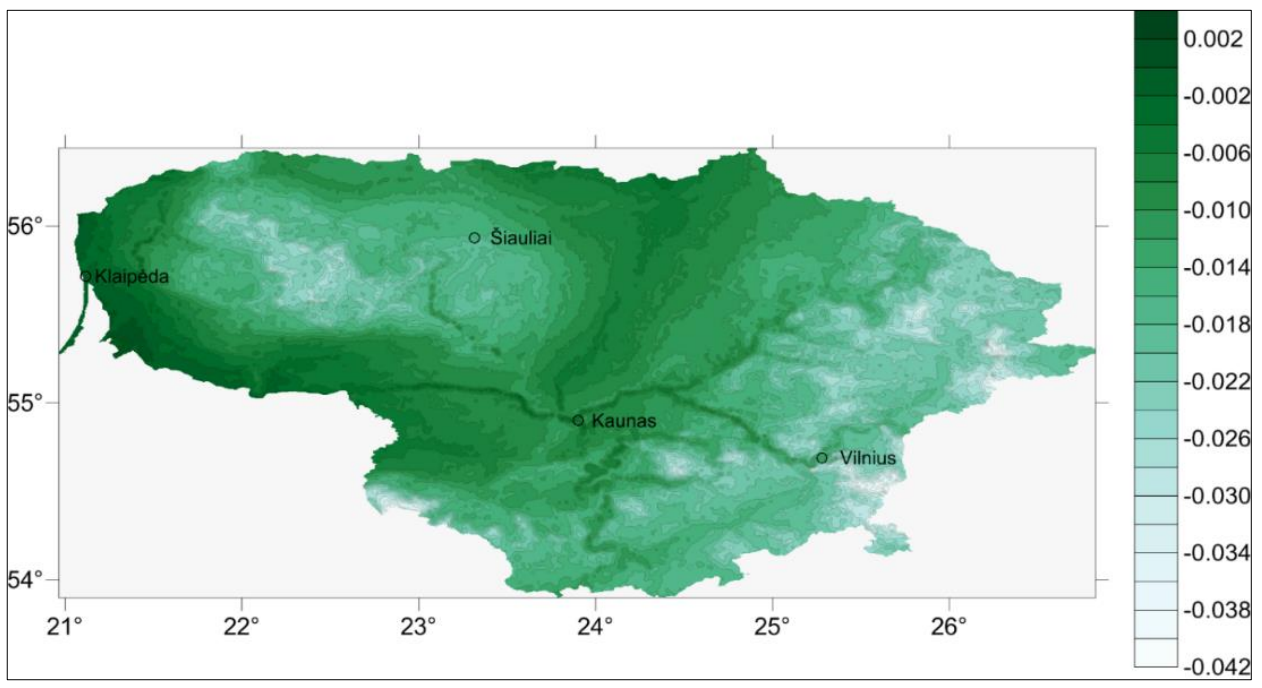

Figure 1. Difference of altitude corrections, mGal

After the calculation of atmosphere correction for points of gravimetric survey, the variation of its values over the territory of Lithuania was shown in Figure 2.

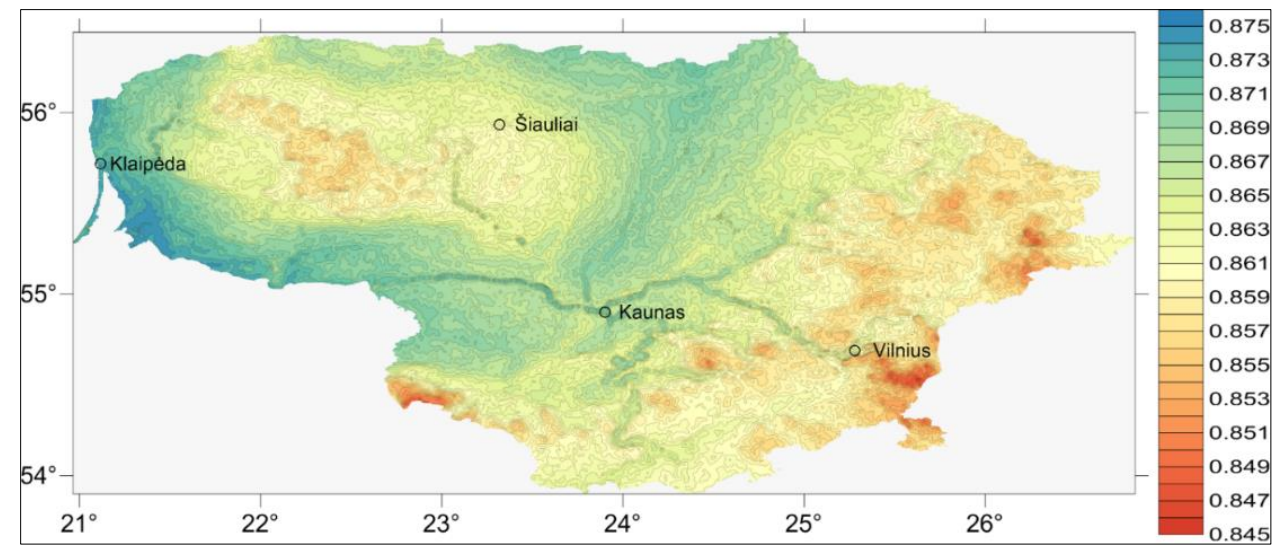

Figure 2. The atmosphere correction, $\mathrm{mGal}$

The values of atmosphere correction vary between $0.845 \mathrm{mGal}$ and $0.874 \mathrm{mGal}$; the average value of the correction is $0.864 \mathrm{mGal}$ and the standard deviation is $0.005 \mathrm{mGal}$.

In points of the gravimetric survey of Lithuania, mixed free-air gravity anomalies (upon taking into account the atmosphere correction) vary between $-28.831 \mathrm{mGal}$ and $42.681 \mathrm{mGal}$. The average value is $-1.585 \mathrm{mGal}$.

If a relief correction is applied to a free-air anomaly, a Faye anomaly is obtained. These mixed anomalies cal be applied in investigation of geoids as well as establishment of altitude anomalies and vertical deflection, because they satisfy the conditions of the Stokes' task.

\section{The effect of quasigeoid undulation}

In tackling geophysical problems or in gravimetric prospecting, application of clean gravity anomalies is purposeful (Bychkov et al., 2015; Hinze et al., 2005). In such cases, ellipsoidal altitudes shall be used instead of normal ones in calculation of gravity anomalies.

Upon applying the formula (4), let's calculate the quasigeoid altitude corrections for gravity anomalies

$$
\Delta \gamma_{80}(\zeta)=0,30877\left(1-0,00142 \sin ^{2} B\right) \zeta-0,75 \cdot 10^{-7} \zeta^{2},
$$

here $\zeta$ - the altitude of quasigeoid.

In Figure 3, the distribution of values of quasigeoid altitude corrections in the territory of Lithuania is shown. 


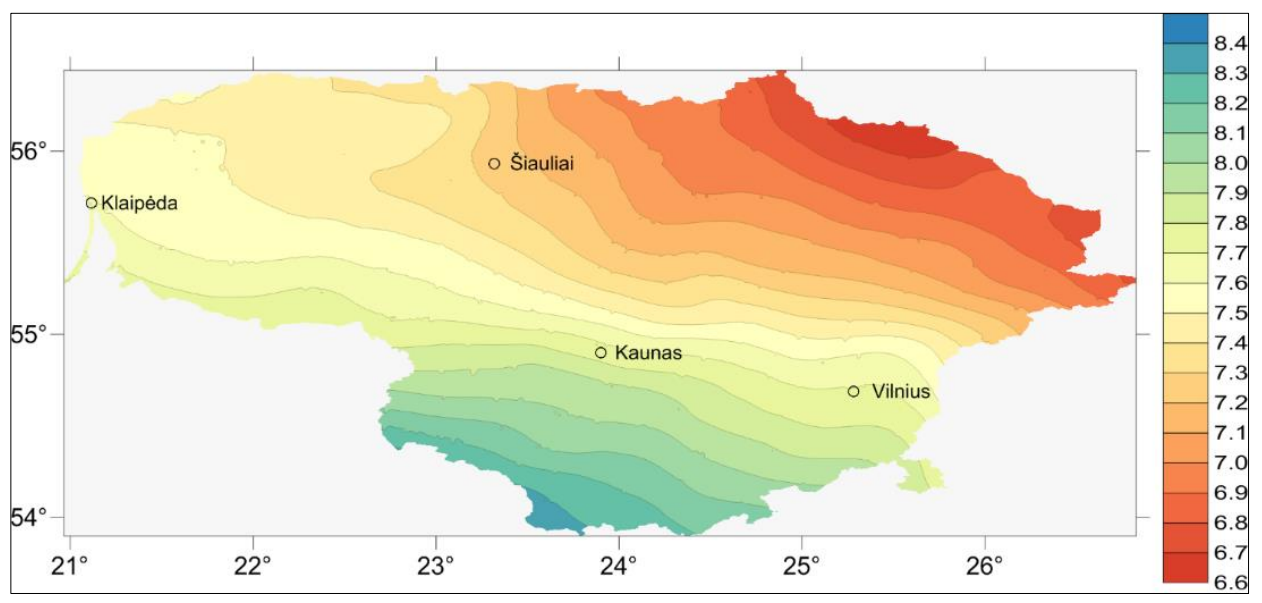

Figure 3. The quasigeoid altitude corrections, mGal

The values of quasigeoid altitude correction for gravity anomalies vary between $6.630 \mathrm{mGal}$ and $8.393 \mathrm{mGal}$. The average value of a correction is $7.466 \mathrm{mGal}$. The standard deviation is $0.377 \mathrm{mGal}$.

If this correction is entered an anomaly, the so called indirect effect (that appears because the measured gravity acceleration and the normal gravity acceleration belong to different points) is eliminated in gravimetric prospecting. The changes of the said correction that cause variations of the quasigeoid's altitudes are more important in gravimetric prospecting, as compared to the absolute value of the correction.

Clean gravity anomalies can be applied for establishing the gravimetric altitude anomalies as well; however, the Neumann - Koch formula shall be applied instead of the Stokes' formula in this case (Hofmann-Wellenhof \& Moritz, 2006):

$$
\zeta=\frac{R}{4 \pi \gamma} \iint_{\omega} N(\psi)(g-\gamma) d \omega
$$

here: $R$ - the Earth's radius; $\gamma$ - the average value of the normal gravity acceleration; $\omega$ - the surface of the unit sphere; $N(\psi)$ - the Neumann - Koch function; $N(\psi)=\operatorname{cosec} \frac{\psi}{2}-\ln \left(1+\operatorname{cosec} \frac{\psi}{2}\right) ; \psi-$ the spherical distance between the point (that the calculation is made for) and the point of integration; $(g-\gamma)$ - the clean gravity anomaly.

Free-air gravity anomalies and Faye anomalies depend on the relief of the territory and vary rapidly, so they cannot be interpolated into points where gravimetric measurements had not been carried out. For this purpose, complete and incomplete topographic reduction anomalies shall be applied.

\section{Complete and incomplete topographic reduction anomalies}

In case of a complete topographic reduction, the influence of the mass between the geoid (or the ellipsoid, if clean anomalies are applied) and the Earth's surface should be eliminated. In this case, the density of water of seas and oceans is increased up to the average density of the Earth crust, and the territories below the geoid are filled with mass of the same density up to its surface. The influence of this joint mass would express the complete topographic reduction $\Delta g_{p t r}$. If we use a system of coordinates where the origin of coordinates coincides with the gravimetric point, the direction of the axis $\mathrm{z}$ - with the direction of gravity, the axes $\mathrm{x}$ and $\mathrm{y}$ are in the horizontal plane (Hofmann-Wellenhof \& Moritz, 2006; Torge, 1989), we can write the following formula:

$$
\Delta g_{p t r}=G \iiint_{v} \frac{\delta z}{r^{3}} d x d y d z
$$

here: $G$ - the gravitational constant; $\delta$ - the density of the Earth crust; $r$ - the distance between the point and the material points (that change the topographic mass) with coordinates $x, y, z ; r=\sqrt{x^{2}+y^{2}+z^{2}} ; v-$ the volume of topographic masses.

The influence of large masses, even situated in other continents, may achieve several milliGals. Of course, within a small territory this influence will be the same. A complete topographic reduction anomaly shall be calculated according to the following formula:

$$
(g-\gamma)_{p t r}=g-\gamma^{0}+\Delta \gamma(H)-\Delta g_{p t r}+\Delta g_{a}(H) .
$$


J. F. Hayford had proposed a formula for calculation of complete topographic reduction. By concentric circles, the total surface of the Earth is divided into zones; the said zones, in their turn, are divided into sectors by radial radii. In this way, the topographic masses are approximated into a system of prisms. The first 15 zones (up to $166.735 \mathrm{~km}$ ) are plane and the remained 18 zones are spherical. In tackling some geophysical problems within very large territories, these anomalies would be the most appropriate.

It is possible to assess the influence of topographic masses up to a certain distance from the point. In such a case, an incomplete topographic reduction $\Delta g_{n t r}$ and the relevant incomplete topographic reduction anomaly shall be calculated

$$
(g-\gamma)_{n t r}=g-\gamma^{0}+\Delta \gamma(H)-\Delta g_{n t r}+\Delta g_{a}(H) .
$$

The distance for assessing the influence of topographic masses shall be chosen upon taking into account the peculiarities of the topographic masses and the character of the problems to be tackled. Usually the distance of $166.735 \mathrm{~km}$ (Hinze et al., 2005) or $200 \mathrm{~km}$ is considered sufficient. If an incomplete topographic reduction is established in a small territory, a spherical or even planar model of the Earth can be applied, and the density of the Earth crust is considered constant. In the assessment of the influence of the topographic masses, the principal components are singled out; they include the influence of the endless plane intermediate layer, the Earth sphericity correction and the relief correction. By the way, the influence of the spherical intermediate layer can be calculated at once. The gravitational pull of the intermediate layer assesses the mass between the horizontal or spherical surface passing through the point of measurements and the chosen datum-surface, for example, the geoid.

\section{Assessment of the influence of the plane intermediate layer}

In practice, for example, while carrying out an interpolation of free-air anomalies and Faye anomalies or tackling problems in gravimetric prospecting, Bouguer anomalies are frequently applied. They are obtained by deduction of gravitational pull of the plane intermediate layer between a point on the Earth surface and geoid from the free-air anomaly. Bouguer anomalies may be interpolated; for them, gravimetric maps are formed. The gravimetric map of the territory of Lithuania includes them as well. In a case of rugged topography, a relief correction is imposed in addition. For some geophysical tasks, another datum-surface (not a geoid) may be chosen; it may be an ellipsoid, a surface with a certain pattern of distribution of the Earth cork density or a surface passing through the lowest point of the relief of the territory under investigation.

Bouguer anomaly of a point on the Earth surface shall be expressed by the following formula:

$$
(g-\gamma)_{\delta}=(g-\gamma)-\Delta g_{\delta}(H)+\Delta g_{r}
$$

here $\Delta g_{\delta}(H)$ is a correction for the endless intermediate layer

$$
\Delta g_{\delta}(H)=2 \pi G \delta H
$$

$G=6.67259 \cdot 10^{-11} \mathrm{~m}^{3} \mathrm{~kg}^{-1} \mathrm{~s}^{-2}-$ the gravitational constant, $\delta$ - Earth crust density; $\Delta g_{r}-$ the relief correction.

The average density of Earth crust $\delta=2.67 \mathrm{~g} / \mathrm{cm}^{3}$. This value of the density is often usable in the geoid studies. For a formation of the gravimetric map of the territory of Lithuania, $\delta=2.3 \mathrm{~g} / \mathrm{cm}^{3}$ was applied. Upon applying certain methods (Bychkov et al., 2015), the average density of Earth crust fit for calculating gravity anomalies for a territory under investigation can be established and applied. Then the value of the density can be made more exact in course of solving geophysical tasks.

In Table 1, the values of gravimetric pull of the intermediate layer upon taking into account its thickness and

\begin{tabular}{|c|c|c|c|c|}
\hline $\mathrm{H} \mathrm{m}$ & 1.85 & 2.09 & 2.30 & 2.67 \\
\hline 10 & 0.776 & 0.876 & 0.964 & 1.119 \\
\hline 100 & 7.756 & 8.762 & 9.643 & 11.194 \\
\hline 300 & 23.268 & 26.287 & 28.928 & 33.582 \\
\hline 500 & 38.781 & 43.812 & 48.214 & 55.970 \\
\hline
\end{tabular}
density are presented.

Table 1. Gravitational pull of the endless intermediate layer, mGal 
We can see that choosing the density of the intermediate layer may cause variation of gravity anomalies up to several tens mGal.

In detailed geophysical research works, a need in accurate assessment of the influence of the intermediate layer may arise. If the intermediate layer consists of m layers with constant density $\delta_{i}$ and thickness $\Delta H_{i}$, the gravitation pull of such an intermediate layer can be expressed by the following formula:

$$
\begin{gathered}
\Delta g_{\delta}(H)=2 \pi G \sum_{i=1}^{m} \delta_{i} \Delta H_{i}, \\
H=\sum_{i=1}^{m} \Delta H_{i} .
\end{gathered}
$$

While tackling geophysical problems, a constant density can be chosen in the beginning; then, upon solving a reverse task in gravimetric prospecting, the density shall be more exactly defined. Then the intermediate layer correction and the relief correction shall be more exactly defined as well (Bychkov et al., 2015).

\section{An assessment of the sphericity of the intermediate layer}

The sphericity correction for the intermediate layer may be calculated according to the following formula (Hinze et al., 2005; LaFehr, 1991):

$$
\Delta g_{\delta s}(H)=2 \pi G \delta(\mu H-\lambda R)
$$

here: $\mathrm{H}$ - thickness of the intermediate layer; $R_{0}=6371.032 \mathrm{~km}-$ the Earth radius; $\alpha=\frac{S}{R_{0}} ; S-$ the radius of the territory under investigation around the gravimetric point; $R=R_{0}+H$,

$$
\begin{gathered}
\mu=\left(\frac{1}{3} \eta^{2}-\eta\right) ; \lambda=\frac{1}{3}\left\{\left(d+f \sigma+\sigma^{2}\right) \sqrt{(f-\sigma)^{2}+k}+p+m \ln \frac{n}{f-\sigma+\sqrt{(f-\sigma)^{2}+k}}\right\} \\
\sigma=R_{0} / R ; \quad \eta=H / R ; \quad d=3 \cos ^{2} \alpha-2 ; \quad f=\cos \alpha ; \quad k=\sin ^{2} \alpha ; \\
p=-6 \cos ^{2} \alpha \sin \left(\frac{\alpha}{2}\right)+4 \sin ^{3}\left(\frac{\alpha}{2}\right) ; \quad m=-3 \sin ^{2} \alpha \cos \alpha ; \quad n=2\left[\sin (\alpha / 2)-\sin ^{2}(\alpha / 2)\right] .
\end{gathered}
$$

In addition to assessment of the sphericity of the intermediate layer, the sphericity should be assessed in calculation of the relief correction; the same radius of the territory under assessment shall be chosen. Usually it is considered to be equal to $166.735 \mathrm{~km}$ (Hinze et al., 2005) or $200 \mathrm{~km}$. In Table 2, the sphericity corrections for the intermediate layer at different radii of the territory and the difference of corrections $\Delta \Delta g_{\delta s}(H)$ are presented.

Table 2. The sphericity corrections for the intermediate layer, $\mathrm{mGal}$ at $\delta=2.67 \mathrm{~g} / \mathrm{cm}^{3}$

\begin{tabular}{|c|c|c|c|}
\hline $\mathrm{H} \mathrm{m}$ & 166.735 & 200.000 & $\Delta \Delta g_{\delta s}(H)$ \\
\hline 10 & & & 0.003 \\
\hline 100 & 0.015 & 0.018 & 0.030 \\
\hline 300 & 0.143 & 0.173 & 0.092 \\
\hline 500 & 0.408 & 0.500 & 0.160 \\
\hline
\end{tabular}

So, within the territory of Lithuania the difference of corrections does not exceed $100 \mu \mathrm{Gal}$.

The distribution of sphericity correction for the intermediate layer in the territory of Lithuania is shown in Figure 4 below.

In points of the gravimetric survey of Lithuania, this correction does not exceed $0.491 \mathrm{mGal}$; its average value is $0.178 \mathrm{mGal}$ and its standard deviation is $0.080 \mathrm{mGal}$.

In assessment of the sphericity of the intermediate layer, the mixed Bouguer anomaly shall be calculated according to the following formula:

$$
(g-\gamma)_{\delta}=(g-\gamma)-\Delta g_{\delta}(H)-\Delta g_{\delta s}(H)+\Delta g_{r} .
$$




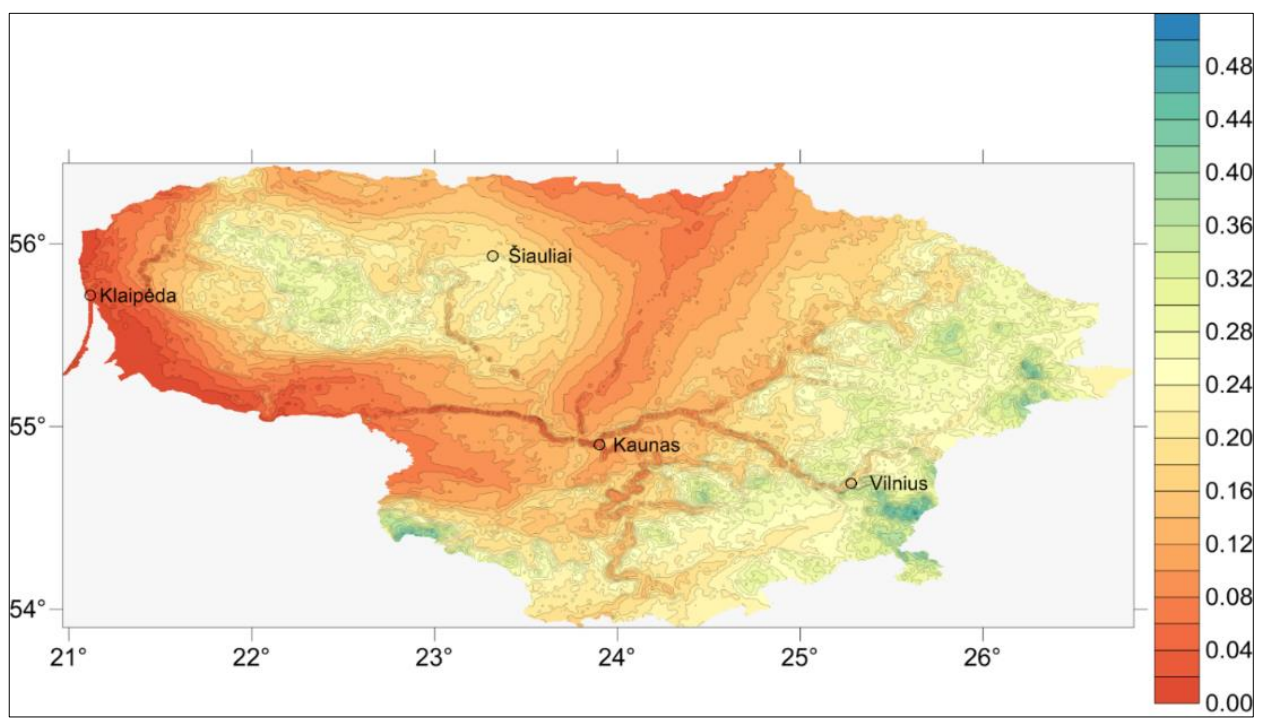

Figure 4. The sphericity correction for the intermediate layer, $\mathrm{mGal}\left(\mathrm{S}=200 \mathrm{~km}, \delta=2.67 \mathrm{~g} / \mathrm{cm}^{3}\right)$

In points of the gravimetric survey, the values of the mixed Bouguer anomalies calculated upon applying the formula (15) vary between $-38.213 \mathrm{mGal}$ and $24.849 \mathrm{mGal}$. The average value is $-13.322 \mathrm{mGal}$.

In formation of the gravimetric map of the territory of Lithuania, the Bouguer anomalies were calculated according to the following formula:

$$
\left(g-\gamma_{H}\right)=g_{z}-\gamma_{H}^{0}+0,3086 H-0,0419 \delta H .
$$

The differences between mixed Bouguer anomalies at $\delta=2.67 \mathrm{~g} / \mathrm{cm}^{3}$ calculated according to the formulas (14) and (15) are shown in Figure 5 below.

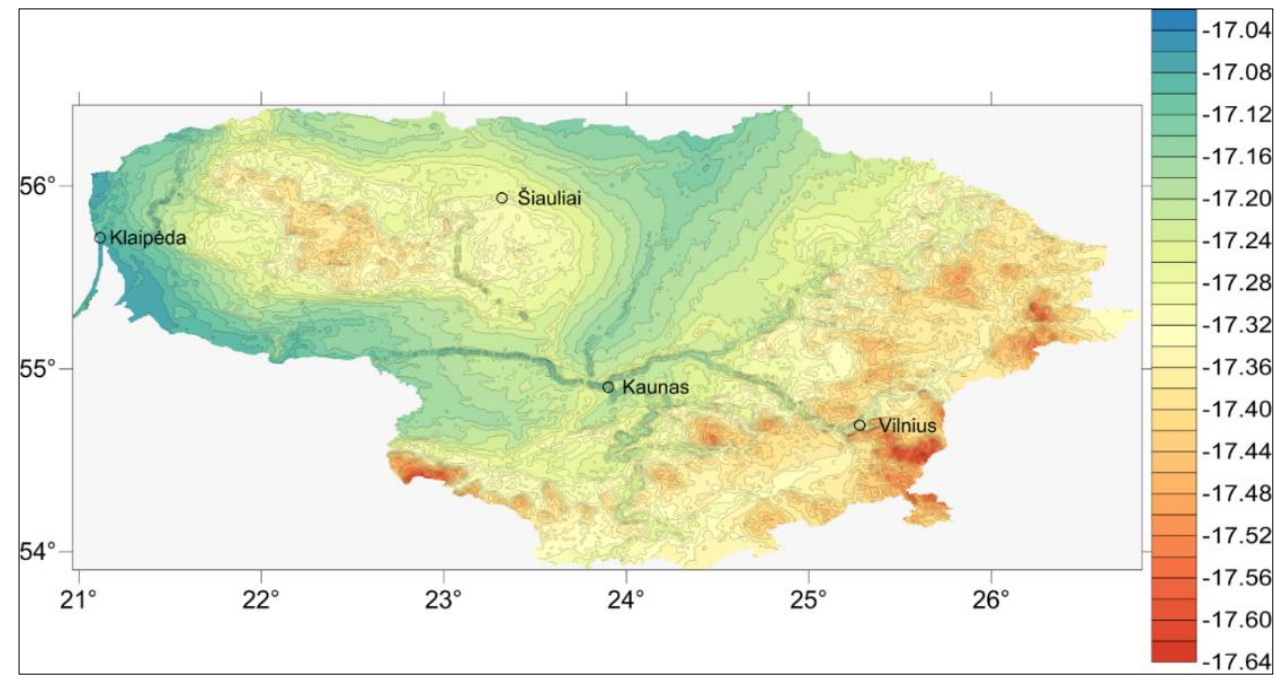

Figure 5. The difference of mixed Bouguer anomalies, mGal

The values of the difference vary between $-17.646 \mathrm{mGal}$ and $-17.059 \mathrm{mGal}$. The average value of the differences is $-17.272 \mathrm{mGal}$. The standard deviation is $0.095 \mathrm{mGal}$.

The differences between clean and mixed Bouguer anomalies calculated according to the formula (15) are shown in Figure 6 below. 


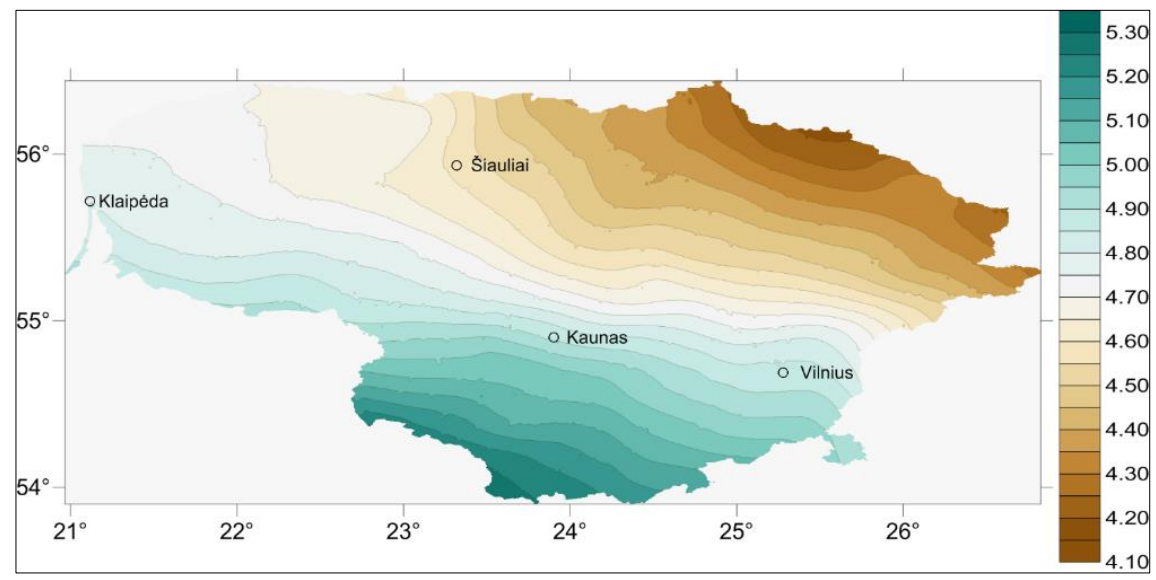

Figure 6. The difference of clean and mixed Bouguer anomalies, mGal

The values of the difference vary between $4.185 \mathrm{mGal}$ and $5.298 \mathrm{mGal}$. The average value of the differences is $4.713 \mathrm{mGal}$. The standard deviation is $0.238 \mathrm{mGal}$.

\section{The relief correction}

The relief correction assesses the deviation of the relief surface from the intermediate layer. The masses over the intermediate layer are eliminated and the pits on it are filled with masses of the same density. In calculation of the relief corrections, the radius of the sector of the territory under assessment depends on the design accuracy of the gravimetric survey. Most frequently, it is equated to $200 \mathrm{~km}$. For establishing the value of the correction, detailed models of the relief are required. The correction is established in course of solving a direct task of gravimetric prospecting. The accuracy of the relief correction should conform to the accuracy of measurements of the acceleration. For establishing the relief correction, the integral described by the formula (7) is limited by the volume $v$ between the surface of the relief and the surface passing through the gravimetric point (plane, sphere or ellipsoid).

Abundant methods for calculating the relief correction exist. The relief is approximated by a set of elementary bodies and their influences are summarized. At present, the relief is frequently approximated by rectangular parallelepipeds (cuboids).

The influence of an homogenous body that's shape is a rectangular parallelepiped with edges parallel to the coordinate planes $\left(x_{1} \leq x \leq x_{2}, y_{1} \leq y \leq y_{2}, z_{1} \leq z \leq z_{2}\right)$ in the origin of the system of coordinates of gravity shall be expressed by the following formula (Torge, 1989; Petroškevičius, 2004):

$$
\begin{aligned}
\Delta g_{s}=-G \delta \mid & x \ln \left(y+\sqrt{x^{2}+y^{2}+z^{2}}\right)+y \ln \left(x+\sqrt{x^{2}+y^{2}+z^{2}}\right)- \\
& -\left.\left.\left.z \arctan \left(\frac{x y}{z \sqrt{x^{2}+y^{2}+z^{2}}}\right)\right|_{z_{1}} ^{z_{2}}\right|_{y_{1}} ^{y^{2}}\right|_{x_{1}} ^{x_{2}} .
\end{aligned}
$$

If the intermediate layer is plane, the value of the relief correction is positive; if the intermediate layer is spherical, the correction can be negative.

On establishing the relief correction, the environment of the gravimetric point shall be divided into zones. Closer to the point, more detailed data on the relief are required. For example, the new standards applicable in North America (Bychkov et al., 2015; Hinze et al., 2005) require using the topographic data obtained by measurements in the distance up to $100 \mathrm{~m}$ from the gravimetric point. In the second zone (in the distance up to $895 \mathrm{~m}$ ), the data on altitudes fit for large-scale topographic maps are applied. In the third zone (up to $166.7 \mathrm{~km}$ ), digital models of the relief with $15^{\prime \prime}$, $1^{\text {' }}$ or 3 ' grids are used. On calculation of a correction, the Earth's curvature is assessed in distances over $14 \mathrm{~km}$ from the gravimetric point. In the first two zones, the relief is approximated by segment rings and in the third zone - by vertical prisms.

In points of the gravimetric survey of Lithuania, the relief corrections were calculated upon applying the TC procedure of GRAVSOFT program package. The relief models developed by the Nordic Geodetic Commission (NKG) were used. The radius of the close zone was $6 \mathrm{~km}$, and the radius of the distant zone was $200 \mathrm{~km}$. In Figure 7, the distribution of values of relief correction in the territory of Lithuania is shown. 


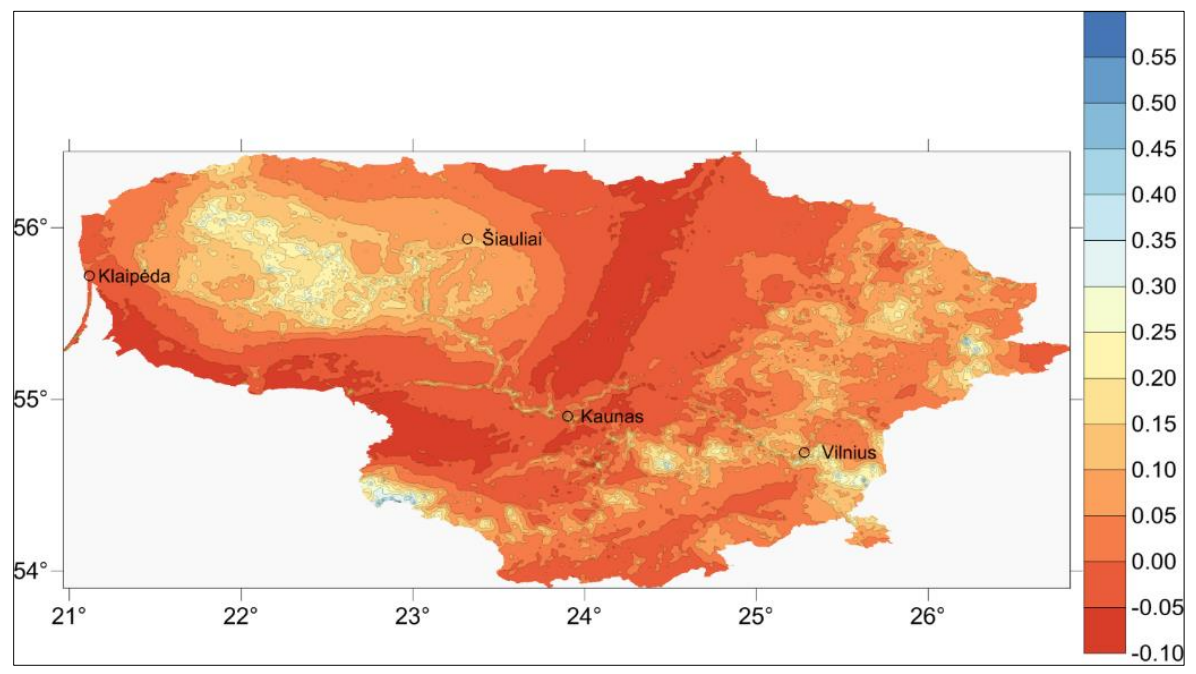

Figure 7. Relief corrections, mGal

The values of relief correction vary between $-0.080 \mathrm{mGal}$ and $0.550 \mathrm{mGal}$. The average value is $0.032 \mathrm{mGal}$ and the standard deviation is $0.074 \mathrm{mGal}$. Upon taking into account the today opportunities for measuring the gravity acceleration, the accuracy of establishing the relief corrections should be improved.

\section{Conclusions}

1. The variation of mixed and clean gravity anomalies in the territory of Lithuania as well as the corrections for them have been assessed.

2. While comparing the atmospheric influence to the influence of the sphericity corrections for the intermediate layer, it may be seen that the sphericity causes a much stronger influence on variations of the anomalies.

3. Use of clean anomalies highlights a considerable influence of altitudes of the geoid on variations of the anomalies.

4. The presented assessments of the anomalies and the corrections for them can be applied for choosing algorithms for calculating anomalies of gravimetric points upon taking into account the character of the problem to be solved and the accuracy of the anomalies.

\section{References}

Birvydienè, R. (2014). Sunkio lauko nevienalytiškumo tyrimu metodikos tobulinimas (Daktaro disertacija). Technika, 160 p. https://doi.org/10.20334/2288-M

Bychkov, S. G., Dolgal, A. S., \& Simanov, A. A. (2015). Vychisleniye anomaliy sily tyazhesti pri vysokotochnykh gravimetricheskikh syemkakh. Perm', UrO RAN. 142.

Hinze, W. J., Aiken, C., Brozena, J., Coakley, B., Dater, D., Flanagan, G., Forsberg, R., Hildenbrand, T. G., Keller, R., Kellogg, J., Kucks, R., Li, X., Mainville, A., Morin, R., Pilkington, M., Plouff, D., Ravat, D., Roman, D., Urrutia-Fucugauchi, J., Veronneau, M., Webring, M., \& Winester, D. (1984). New standards for reducing gravity data: The North American gravity database 2005. Geophysics, 70(4), J25-J32. https://doi.org/10.1190/1.1988183

Hofmann-Wellenhof, B., \& Moritz, H. (2006). Physical geodesy. Springer Wien New York, 403.

LaFehr, T. R. (1991). An exact solution for the gravity curvature (Bullard B) correction. Geophysics, 56(8), 1179-1184. https://doi.org/10.1190/1.1443138

LaFehr, T. R., \& Nabighian, M. N. (2012). Fundamentals of gravity exploration. Society of Exploration Geophysicists. 218. https://doi.org/10.1190/1.9781560803058

Moritz, H. (1980). Geodetic reference system 1980. Bulletin géodésique, 58(3), 388-398. https://doi.org/10.1007/BF02519014

Nozaki, K. (2006). The generalized Bouguer anomaly. Earth Planets and Space, 58(3), 287-303. https://doi.org/10.1186/BF03351925

Petroškevičius, P. (2004). Gravitacijos lauko poveikis geodeziniams matavimams. Technika.

Petroškevičius, P., Paršeliūnas, E. K., Birvydienė, R., Popovas, D., Obuchovski, R., \& Papšienè, L. (2014). The quality analysis of the national gravimetric network of Lithuania. Geodetski vestnik. Ljubljana: Association of Surveyors of Slovenia, 58(4), 746755. https://doi.org/10.15292/geodetski-vestnik.2014.04.746-755

Torge, W. (1989). Gravimetry. Berlin, New York: de Gruyter. 